\title{
Professor Joachim Mössner Retires as Editor-in-Chief
}

\author{
Ernst Klar $^{\mathrm{a}}$ Georg Kähler ${ }^{\mathrm{b}} \quad$ Markus F. Neurath ${ }^{\mathrm{c}}$ \\ a Department of General, Thoracic, Vascular and Transplantation Surgery, University of Rostock, Rostock, Germany; \\ ${ }^{b}$ Central Interdisciplinary Endoscopy Unit, Medical Faculty Mannheim, Heidelberg University, University Medical Center Mannheim, \\ Mannheim, Germany; \\ ${ }^{\mathrm{c}}$ Medical Clinic 1, Friedrich-Alexander-University Erlangen-Nürnberg, Erlangen, Germany
}

After more than 22 years of continuous commitment to the journal, first as a member of the Editorial Board, then as Associate Editor, and finally as Editor-in-Chief, Professor Joachim Mössner has decided to retire as Editor-in-Chief of Visceral Medicine. We would like to express our warmest thanks for the excellent cooperation and his outstanding contribution throughout all these years.

He represented the field of gastroenterology in the journal's interdisciplinary setting with the full spectrum of this discipline. Professor Mössner graduated from the University of Würzburg in 1976 and had his training in gastroenterology in Würzburg where he was appointed Associate Professor of Internal Medicine in 1989. Subsequently, he became Professor of Internal Medicine and Chairman as Director of the 'Klinik und Poliklinik für Gastroenterologie und Rheumatologie' at the University of Leipzig, a position he holds until this day. His main field is the pathogenesis and treatment of acute and chronic pancreatitis including genetic risk factors.
Professor Mössner was Dean of the Medical Faculty, University of Leipzig, President of the German Association of Gastroenterology in 1999, and President of the German Association of Internal Medicine 2011-2012. He received multiple scientific awards and was elected as a member of the world's oldest scientific academy, the German National Academy of Sciences (Leopoldina), in 1999.

Professor Mössner is an outstanding academic gastroenterologist who was (and remains) a great addition to our journal. He supported us with his extraordinary expertise during a major transition phase from a solid German journal to an international profile concerning issue editors, a new title, layout, and the change to English. As fellow Editors-in-Chief, it was a great pleasure for us to work with Professor Mössner on these challenges, and thus we appreciate a lot that he has decided to stay affiliated with the journal as a member of the Editorial Board in the future. We want to express our deepest thanks for his commitment yet again and wish him all the best for his new period of life after his imminent retirement.

\section{KARGER}

() 2017 S. Karger GmbH, Freiburg
Prof. Dr. med. Ernst Klar

Abteilung für Allgemeine, Thorax-, Gefäß- und Transplantationschirurgie

Universitätsmedizin Rostock

Schillingallee 35, 18057 Rostock, Germany

Ernst.Klar@med.uni-rostock.de 